\title{
Vallecular Cyst in a 1 Month Old Infant
}

\author{
Coban $\mathrm{K}^{1^{*}}$, Bas $\mathrm{C}^{1}$ and Aydin $\mathrm{E}^{2}$ \\ ${ }^{1}$ Department of Otorhinolaryngology, Baskent University Alanya Research and Application Center, Antalya, Turkey \\ ${ }^{2}$ Department of Otorhinolaryngology, Baskent University Ankara Hospital, Ankara, Turkey
}

*Corresponding author: Coban K, Department of Otorhinolaryngology, Başkent University Alanya Research and Application Center, Antalya, Turkey, Tel: +90 53272541 96, E-mail: kubracob81@gmail.com

Citation: Coban K, Bas C, Aydin E (2018) Vallecular Cyst in A 1 Month Old Infant. J Otolaryngol Res 1: 105

Article history: Received: 16 May 2018, Accepted: 3 July 2018, Published: 6 July 2018

\begin{abstract}
Vallecular cyst (VC) is a life threatening cause of upper respiratory system obstruction, especially in newborns and infants. They are caused by ductal obstruction of minor salivary or mucous glands. They may occur anywhere in the larynx, most commonly in the lingual surface of the epiglottis. These cysts are benign in nature, however, cause high morbidity and mortality, thus, high index of suspicion is crucial. Here we presented a 1 month old infant with severe stridor and feeding difficulties caused by an enlarged VC, and reviewed the optimal treatment strategies for this rarely seen pathology.
\end{abstract}

Keywords: Vallecular Cyst; Stridor; Breathing Disorders; Feeding Disorders; Laryngeal Cysts

\section{Introduction}

Vallecular cyst (VC) is a rarely seen but life threatening cause of upper respiratory system obstruction in newborns and infants. Nearly $10.5 \%$ of congenital laryngeal cysts are VC [1]. Tsai, et al. reported an incidence of 5.3 cases/100.000 live births [1,2]. It is also known as mucus retention cyst, epiglottic cyst, ductal cyst and tongue base cyst [2,3]. Coughing, dyspnea, stridor, failure to thrive, feeding difficulties, voice changes are the most commonly observed symptoms [3,4]. Although these cysts are benign in nature, due to it's high morbidity and mortality, high index of suspicion is crucial to diagnose this pathology. Here we present an infant with severe stridor and feeding difficulties caused by an enlarged VC, and discuss our treatment strategies with a thorough literature review.

\section{Case Report}

A 1 month old male infant was referred to our clinic with a history of feeding and breathing difficulties since birth. When he was 15 days old, they had attended to another clinic elsewhere and the ultrasonography that had been performed there, reported a $2 \times 2.5 \mathrm{~cm}$ cystic mass in the midline of the neck. In his physical examination, inspiratory stridor, suprasternal retraction was noticed. Other system examinations were within normal limits. Flexible nasopharyngoscopy revealed a 'sun rising', nearly 2-3 $\mathrm{cm}$ mass, located between the base of the tongue and epiglottis complicating the visualisation of the airway. The patient was hospitalized. Thyroid scans and hormone levels were within normal limits. Direct laryngoscopy under general anesthesia was promptly planned to evaluate the extent of the cyst. The patient was in Trendelenburg position with hyperextension of the neck. Rigid laryngoscopy blade was gently inserted, advanced and directed in a midline approach. The epiglot could not be visualized due to the lesion. Thus aspiration of the cyst was performed in order to visualize the entire laryngeal structures, to rule out vascular lesions and to facilitate the complete excision of the cyst. The vascular structures over the cyst membrane was cauterized. The cyst was completely excised (Figure 1).

Histopathological evaluation was reported as a 'benign cystic lesion'. Patient's symptoms releived immediately in the early postoperative period. On the post-operative first week, control video-laryngoscopy showed no evidence of recurrence. The patient had no further airway and nutritional problems or recurrence of the cyst in the 6 months follow-up.

\section{Discussion}

Vallecular cysts are caused by ductal obstruction of minor salivary or mucous glands [5]. They are observed anywhere in the larynx, most commonly in the lingual surface of the epiglottis as in our case [2]. VC can ocur at any age, however, they are frequently seen in neonates and infants with median ages at diagnosis are 3-4 days [2]. The patient described here was 1 month old. The delay of diagnosis of these cases may commonly be due to low suspicion index of clinicians. 


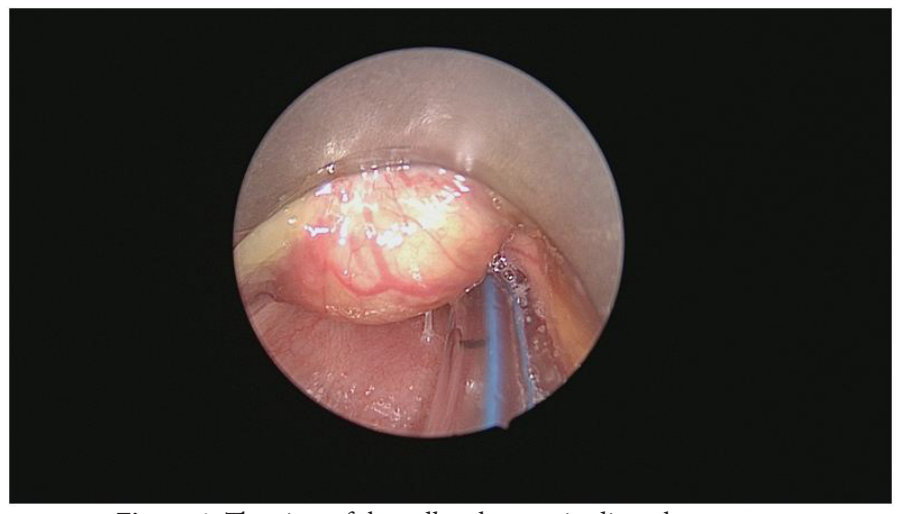

Figure 1: The view of the vallecular cyst in direct laryngospy

In this case, the major symptoms were stridor and feeding difficulties which leaded to poor weight gain. Laryngolomalacia may co-occur and complicate the condition however, in our case it did not exist $[1,2]$.

Thyroid hormone levels and thyroid gland scanning is essential to rule out lingual thyroid $[2,6]$. These tests were within normal limits in this present case. Lymphangioma, hemangioma, cystic hygroma, hamartoma, teratoma, thyroid remnant cyst, lingual thyroid, thyroglossal duct cyst should be considered in the differential diagnosis of VC [2-5,7].

For the radiologic examination, CT scan or MRI are required to accurately demonstrate the size, cystic nature, extent of the mass and make a precise differential diagnosis [4,8]. Direct laryngoscopy is the major diagnostic tool for a definite diagnosis [4]. In our case ultrasonographic evaluation was performed elsewhere, and, a cystic mass was reported. CT or MRI were not considered due to the potential risks of radiation in CT, and additional need for anesthesia during MRI. In order to avoid possible airway complications due to time delay, direct laryngoscopy and surgical excision following flexible fiberoptic endoscopic evaluation was decided. In addition, fine needle aspiration under ultrasonography, prior to surgery, was not considered since this procedure in a newborn baby would require sedation that could deteriorate the signs and symtoms of the patient.

The treatment of VC is complete surgical excision, endoscopic marsupialization, aspiration of the cyst [2,4,5,9]. Suzuki et.al favoured marsupialization due to negligible recurrence rates compared to complete surgical excision [9]. However Rodriguez et al suggested complete remowal of the cyst to prevent relapse [10]. Marsupialization may not resolve all the symptoms if laryngomalacia is associated [11]. These cysts have been reported to have high recurrence rates following fine needle aspiration [12]. Taking the age of these patients into account, fine needle aspiration requires sedation which may cause worsening of the clinical conditions. Complete surgical excision was the treatment of choice in this patient.

\section{Conclusion}

Vallecular cyst may be life threatening. Thus special attention of both the care providers and clinicians are necessary. Clinicians should always consider VC in the differential diagnosis of an infant with stridor, especially in persistent and severe cases. Timely management is crucial to avoid sudden upper respiratory collapse and death.

\section{Conflict of Interest}

All the authors declare that they have no conflict of interest regarding the publication of this study.

\section{References}

1. Tsai YT, Lee LA, Fang TJ, Li HY (2013) Treatment of vallecular cysts in infants with and without coexisting laryngomalacia using endoscopic laser marsupialization: fifteen-year experience at a single-center. Int J Pediatr Otorhinolaryngol 77: 424-8.

2. AlAbdulla AF (2015) Congenital Vallecular Cyst Causing Airway Compromise in a 2-Month-Old Girl. Case Rep Med 975859.

3. Mahajan V, Mathew JL, Singh M, Gupta R, Das A (2008) Vallecular cyst-revisited. Indian J Pediatr 75 :1081-2.

4. Tuncer U, Aydogan LB, Soylu L (2002) Vallecular cyst: a cause of failure to thrive in an infant. Int J Pediatr Otorhinolaryngol 65: 133-5.

5. Khode SR, Gosrani N, Golhar S, Vedi J (2014) Congenital vallecular cyst with polydactyly - A rare cause of stridor and failure to thrive. Med J Malaysia 69: 101-2. 6. DeSanto LW, Devine KD, Weiland LH (2015) Cysts of the larynx--Classification. Laryngoscope 125: 2629.

7. Gogia S, Agarwal SK, Agarwal A (2014) Vallecular cyst in neonates: case series-a clinicosurgical insight. Case Rep Otolaryngol 764860.

8. Woo EK, Connor SE (2007) Computed tomography and magnetic resonance imaging appearances of cystic lesions in the suprahyoid neck: a pictorial review. Dentomaxillofac Radiol 36: 451-8.

9. Suzuki J, Hashimoto S, Watanabe K, Takahashi K (2011) Congenital vallecular cyst in an infant: case report and review of 52 recent cases. J Laryngol Otol 125 : 1199-203.

10. Rodríguez H, Cuestas G, Solernou V (2015) Congenital vallecular cyst in an infant. Acta Otorrinolaringol Esp 66: 59-60.

11. Marseglia L, D’Angelo G, Impellizzeri P, Salvo V, Catalano N et al. (2017) Neonatal stridor and laryngeal cyst: Which comes first? Pediatr Int 59: 115-7.

12. Reiersen DA, Gungor AA (2014) Airway management in an infant with a giant vallecular cyst. Am J Otolaryngol 35: 261-4. 